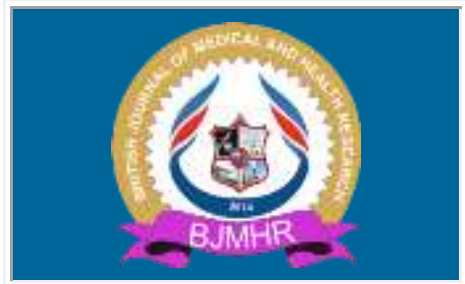

\title{
BJMHR
}

British Journal of Medical and Health Research Journal home page: www.bjmhr.com

\section{Analgesic, Anti-Inflammatory and Anti-Arthritic Effects of Siddha Herbo-Mineral Formulation 'Thiriloga Chindhamani Pills' In Animal Models}

\author{
Anlin Michel ${ }^{1 *}$, Nalina Sarasawathi $\mathbf{K}^{\mathbf{2}}$, Velpandian $\mathbf{V}^{\mathbf{2}}$ \\ 1.Velumailu Siddha Medical College, Sriperumbudur, Kancheepuram, Tamil Nadu \\ 2.Faculties of Gunapadam (Pharmacology), Government Siddha Medical College, \\ Arumbakkam, Chennai, TN, India.
}

\section{ABSTRACT}

Thiriloga Chindhamani Pills (TCP) is commonly used in Siddha system of medicine for its analgesic, anti-inflammatory and anti-arthritic properties. However, these activities have not been scientifically validated through experimental procedures and clinical trials. So the present work was carried out to evaluate the above activities of TCP in rats. Hot Plate model was used to determine the analgesic activity. Two doses of TCP (100 mg and $200 \mathrm{mg} / \mathrm{kg}$ ) was used and Diclofenac Sodium was used as standard. Among the two doses $200 \mathrm{mg} / \mathrm{kg}$ showed highly significant analgesic activity indicated the analgesic activity of TCP in dose dependent manner. Evaluation of anti-inflammatory activity was carried out by carrageenan induced acute inflammatory model in rats. TCP100, TCP200 and reference drug Indomethacin was administered. The results showed that there was a significant difference in oedema size between all the tested groups. TCP 200 exhibited highly significant effect which is similar to that of standard drug. Evaluation of the antiarthritic activity of TCP was evaluated on Freund's complete adjuvant induced arthritic model. Two doses of TCP (100 and $200 \mathrm{mg} / \mathrm{kg}$ ) and the reference drug Prednisolone $10 \mathrm{mg} / \mathrm{kg}$ were administered. Both the positive control and two doses of Thiriloga Chindhamani Pills decreased the inflammatory process and TCP 200 significantly decrease the inflammation when compared to the control. This work has shown that Thiriloga Chindhamani Pills have analgesic, anti-inflammatory and anti-arthritic activities, which would justify their traditional use in Siddha system of medicine.

Keywords: Thiriloga Chindhamani Pills, Analgesic activity, Anti-inflammatory activity, Antiarthritic activity

Please cite this article as: Michel A et al., Analgesic, Anti-Inflammatory and Anti-Arthritic Effects of Siddha Herbo-Mineral Formulation 'Thiriloga Chindhamani Pills' In Animal Models. British Journal of Medical and Health Research 2019. 


\section{INTRODUCTION}

The Siddha System of Medicine is an Indian medical system and one of the oldest medical system that originated before prehistoric period. Medicines of this system contains single herb, poly-herbal formulations, minerals, metal and animal origin to treat various ailments including Rheumatoid arthritis. Rheumatoid arthritis is an inflammatory autoimmune related disorder that affects multiple symmetric involvement of joints, connective tissues, muscle, tendons and fibrous tissues. It tends to strike during the most productive years of adulthood, between the ages of 20 and 40, and is a chronic disabling condition often causing pain and deformity $\left({ }^{1}\right)$. Genes, environmental factors, and hormones may play roles in the development of rheumatoid arthritis $\left({ }^{2}\right)$. Often, symptoms come on gradually over weeks to months $\left({ }^{3}\right)$. RA affects about 24.5 million people as of $2015\left(^{4}\right)$. This is between 0.5 and $1 \%$ of adults in the developed world with 5 and 50 per 100,000 people newly developing the condition each year $\left(^{5}\right)$. Onset is most frequent during middle age and women are affected 2.5 times as frequently as men. In 2013, it is resulted in 38,000 deaths up from 28,000 deaths in $1990\left({ }^{6}\right)$. Rheumatoid arthritis (RA) affects about $0.92 \%$ of adult population in India $\left(^{7}\right)$.

The goals of treatment are to reduce pain, decrease inflammation, and improve a person's overall functioning $\left({ }^{8}\right)$. Analgesics, corticosteroids, NSAIDs, DMARDs and biologics are used to treat and slow the progression of disease $\left({ }^{2,9}\right)$. However, the adverse reactions and toxicity associated with use of these drugs which may limit their long-term use $\left({ }^{10}\right)$.

These unwanted effects warrants a continuous search and need for effective and safe traditional anti-arthritic medicines. In Siddha system of medicine, Thiriloga Chindhamani pills is one of the herbo-mineral formulation used in the treatment of RA and other inflammatory conditions. However, no scientific investigation has been carried out for its analgesic, anti-inflammatory and anti-arthritic potentials. It is in this perspective that this present work was carried out to validate the analgesic, anti - inflammatory and anti-arthritic activities using hot plate method, carrageenan model of inflammation and adjuvant induced arthritis respectively in animal models.

\section{MATERIALS AND METHOD}

\section{Materials for the test drug}

The raw drugs required for the preparation of Thiriloga Chindhamani pills as mentioned in Siddha classical text 'Veeramamunivar Vagada Thirattu' $\left({ }^{11}\right)$. The ingredients are Mercury, Sulphur, Borax, Rock salt impure and Lemon juice.

\section{Collection, Identification of the test drug}

All the ingredients except lemon were procured from authenticated country drug shop at Parry's corner, Chennai, Tamilnadu. Fresh Lemons were purchased from Koyembedu market, 
Chennai. All the above were identified and authenticated by the experts of department of Gunapadam (Pharmacology) and botanist of Government Siddha Medical College, Chennai. Specimen samples of each have been kept in the department for future reference.

\section{Purification and preparation of the trial drug}

All the raw materials were purified according to the Siddha classical literature $\left({ }^{12,13}\right)$. After purification, Mercury and Sulphur were taken together in a stone mortar and triturated into fine black powder. Then the Rock salt was added to the above and ground well. To the ingredients Lemon juice was added little by little and again the content was ground for 6 hours to get a paste which was made into a disc and kept in a Bronze vessel. This paste was kept in mud pot coated with lemon juice allowed for complete drying. Then bronze vessel was tilted along with the disc upside down over the mud pot. Edges of the vessel sealed with clay smeared cloth. Then the pot was heated in kamalakini (medium flame) for 12 hours and it was allowed to cool and the sublimate that was formed in the upper part was collected. Borax powder was added to the sublimate and ground well with lemon juice for 3 hours and rolled into kundrimani sized pills (130mg). After that the pills were dried and preserved in a bottle. Then it was labelled as Thiriloga Chindhamani pills (TCP).

\section{Experimental animals}

Healthy Wistar albino rats weighed between 150-200 gm were purchased from a diseasefree animal house of Tanuvas, Madhavaram, Chennai. The animals were fed with food and water supplied by Sai Meera foods Pvt ltd Bangalore. They were maintained under standard conditions of temperature $\left(25^{\circ} \mathrm{C} \pm 3{ }^{\circ} \mathrm{C}\right)$, relative humidity between $30 \%$ and $70 \%,(12 / 12$ h) light/dark cycle. Then transferred to the laboratory, seven days prior to the experiments for acclimatization to the environment. Protocols for the study were approved by the Institutional Animal Ethical Committee (IAEC) of C.L. Baid Metha college of Pharmacy, Chennai, Tamil Nadu, India (Approval No: IAEC / XLVIII /15 / CLBMPC / 2016) and the study was conducted in accordance with CPCSEA guidelines.

\section{Drugs and chemicals}

The powdered form of Thiriloga Chindhamani pills (TCP) was mixed uniformly in 5\% CMC to achieve $100 \mathrm{mg} / \mathrm{ml}$ as main stock solution and used in this study. Freund's Complete Adjuvant Injection (Difco Lab. USA), Mineral oil (SBD Chemicals), Saline (Wokhardt Laboratories Ltd. Bombay- 400124. Diclofenac sodium, Indomethacin and Prednisolone were purchased from Apollo pharmacy at Chennai. All other reagents and chemicals used in this study were of analytical grade.

\section{Evaluation of Analgesic activity \\ Eddy's Hot Plate Test}


Hot-plate test (Hot/Cold Plate Model-35100- 001, UGO Basil, Italy) was employed for measurement of analgesic activity as previously described by Lanhers et al. and modified by Ojewole $\left({ }^{14,15}\right)$. The temperature was regulated at $55 \pm 0.5^{\circ} \mathrm{C}$ to prevent skin damage of the rat and maintain normal sensitivity.

Rats were divided into four groups consisting of six animals in each group. Group I animals were administered the vehicle (saline). The animals of Group II and III received test samples at the doses of TCP 100 and TCP $200 \mathrm{mg} / \mathrm{kg}$ body weight respectively. Group IV (Positive control) received standard drug Diclofenac Sodium at the dose of $10 \mathrm{mg} / \mathrm{kg} \mathrm{b.w}$.

The rats of each group were placed in the beaker (on the hot plate) in order to obtain its response to electrical heat induced pain stimulus. Licking of the paws or jumping out of the beaker was taken as an indicator of the animal's response to heat-induced pain stimulus. A cut off period of $30 \mathrm{sec}$, was observed to avoid damage to the paw. Reaction time was recorded when animals licked their fore or hind paws or jumped at 0, 30, 6090 and 120 min after oral administration of the samples. Before treatment, the reaction time was taken once. The mean of this determination constituted initial reaction time before treatment of each group of rats.

\section{Evaluation of Acute Anti-inflammatory activity}

\section{Carrageenan- Induced Rat paw oedema method}

The anti-inflammatory activity of the ethanol extract was investigated on carrageenan induced inflammation in rat paw following an established method $\left({ }^{16}\right)$. Rats were randomly divided into five groups, each consisting of six animals, of which group I was kept as control giving 3\% gum acacia $10 \mathrm{ml} / \mathrm{kg}$ p.o. Group-II (Carrageenan) received $0.1 \mathrm{ml}$ of $1 \% \mathrm{w} / \mathrm{v}$ suspension of carrageenan S.C. Group III was standard which received Indomethacin $40 \mathrm{mg} / \mathrm{kg}$ p.o as the reference standard for comparison while Group IV and Group V were given the test material at the doses of 100 and $200 \mathrm{mg} / \mathrm{kg}$ body weight respectively.

One hour after the oral administration of the test materials, $0.1 \mathrm{ml}$ of $1 \% \mathrm{w} / \mathrm{v}$ suspension of carrageenan was injected into sub-plantar region of the left hind paw to all the groups. The paw volume was measured at 1, 2, 3, 4, and $5 \mathrm{hr}$ using Plethysmometer (Model 7150 UGO Basile, Italy). Oedema was expressed as the mean increase in paw volume relative to control animals. The right hind paw served as a reference non-inflamed paw for comparison. The average percentage increase in paw volume with time was calculated and compared against the control group. Percentage inhibition was calculated using the formula:

$\%$ Inhibition of paw oedema $=\mathrm{V}_{\mathrm{c}}-\mathrm{V}_{\mathrm{t}} \quad \mathrm{x} 100$

$$
\mathrm{Vc}
$$

Where, Vc and Vt represent average paw volume of control and treated animal respectively.

Evaluation of anti-rheumatic activity of TCP on CFA induced arthritis in rats: 


\section{Experimental design}

Thirty wistar albino rats were randomly divided into five groups, each comprised of six rats. Group I and Group II served as control (Normal control and arthritic control respectively). Group III and Group IV were given daily oral doses of TCP 100 and 200 mg/kg body weight respectively. Group V served as positive control received a standard drug prednisolone $(10 \mathrm{mg} / \mathrm{kg})$. After 24 hours of medications, arthritis was induced in all rats except group I (normal control) by administration of subcutaneous injection of Freund's complete adjuvant into the sub plantar region of the right hind paw $\left({ }^{17}\right)$. Administration of test drugs (TCP100 and TCP200) and standard drug (prednisolone) continued for 14 days. All the rats were maintained on the balanced diet and water ad libitum throughout the experiment period.

The hind paws of rats were measured with a water replacement plethysmometer before immunization with FCA (baseline, day 0) and on days 1, 7, 14 and 21 after immunization throughout the total experiment. Paw swelling at each time point was defined as the increase in paw volume since immunization, given in millilitres.

At the end of experiment, the increase in the thickness of the injected foot of the rats of groups III, IV and V were compared with that of the Group II (arthritic control). During the experiment, body weight and food intake were also recorded. At the end of the trial period, total food intake, body weight and food efficiency were calculated and compared with control groups.

The arthritic severity in each paw was evaluated by a macroscopic scoring system ranging from 0 to 4: 0 - paws with no swelling and focal redness; 1 - paws with swelling of finger joints; 2 - paws with mild swelling of ankle or wrist joints; 3 - paws with severe inflammation of the entire paws; 4 - paws with deformity or ankylosis. The cumulative score for all four paws of each rat was used as the polyarthritis index with a maximum value of $16 .^{[18]}$

After the experimental period, the rats fasted for 16 hours and blood samples were taken from the eye vein orbital of the anaesthetized rats for the determination of haematological parameters include $\mathrm{Hb}$, Total RBC, Total WBC and ESR.

\section{Arthritis evaluation (articular index)}

The clinical symptoms of arthritis in all four limbs were evaluated according to visual appearance by two observers, who were unaware of the identity of the animal groups. The scores were rated on a scale of $0-4$ for each knee joint: $0=$ no swelling or erythema, $1=$ slight swelling and/or erythema, 2 = low to moderate oedema, $3=$ pronounced oedema with limited joint usage, 4 = excess oedema with joint rigidity. The mean articular index score was given for each foot of adjuvant induced arthritis rat. The total score for each animal was then calculated and used as an articular index with a maximum value of 16 . 


\section{Statistical Analysis}

The data are expressed as the mean \pm SEM and analysed by one-way analysis of variance (ANOVA) followed by Dunnett's t-test. $\mathrm{P}$ value $<0.05$ was considered as significance. All statistical tests were carried out using SPSS statistical software.

\section{RESULTS AND DISCUSSION}

\section{Analgesic Activity}

In the present study, the analgesic activity of Thiriloga Chindhamani pills was assessed by using hotplate method in rats which was represented in Table 1 and Figure 1. Thiriloga Chindhamani pills showed significant analgesic activity at 100 and 200mg/kg, p.o dose compared with normal control and standard groups. Among the two doses $200 \mathrm{mg} / \mathrm{kg}$ showed highly significant analgesic activity at reaction time $120 \mathrm{~min}(22.22 \pm 1.66)$ and slightly lower than the standard drug Diclofenac (24.26 \pm 2.22$)$ indicated the analgesic activity of TCP in dose dependent manner.

Table 1. Effect of Thiriloga Chindhamani Pills on latency to hot plate test

\begin{tabular}{llllll}
\hline Dose & 0 min & 30min & 60 min & 90 min & 120 min \\
\hline Control & $7.80 \pm 1.45$ & $13.76 \pm 1.55$ & $14.88 \pm 1.21$ & $12.96 \pm 1.16$ & $15.20 \pm 1.12$ \\
Diclofenac & $11.2 \pm 1.17$ & $13.96 \pm 1.28$ & $21.10 \pm 2.34^{* *}$ & $23.36 \pm 2.44^{* *}$ & $24.26 \pm 2.22^{* *}$ \\
TCP 100mg & $8.13 \pm 0.72$ & $11.4 \pm 1.43$ & $15.70 \pm 1.24^{*}$ & $17.6 \pm 1.24^{*}$ & $18.88 \pm 1.26^{*}$ \\
TCP 200mg & $9.45 \pm 1.18$ & $12.80 \pm 1.12$ & $16.22 \pm 1.22^{*}$ & $18.22 \pm 1.42^{*}$ & $22.22 \pm 1.66^{* *}$ \\
\hline
\end{tabular}

Data are represented as the mean $\pm S E M,(n=6) ; * p<0.05$, **p<0.01, were considered significant in comparison with control.

\section{Analgesic effect of Thiriloga Chindhamani Pills}

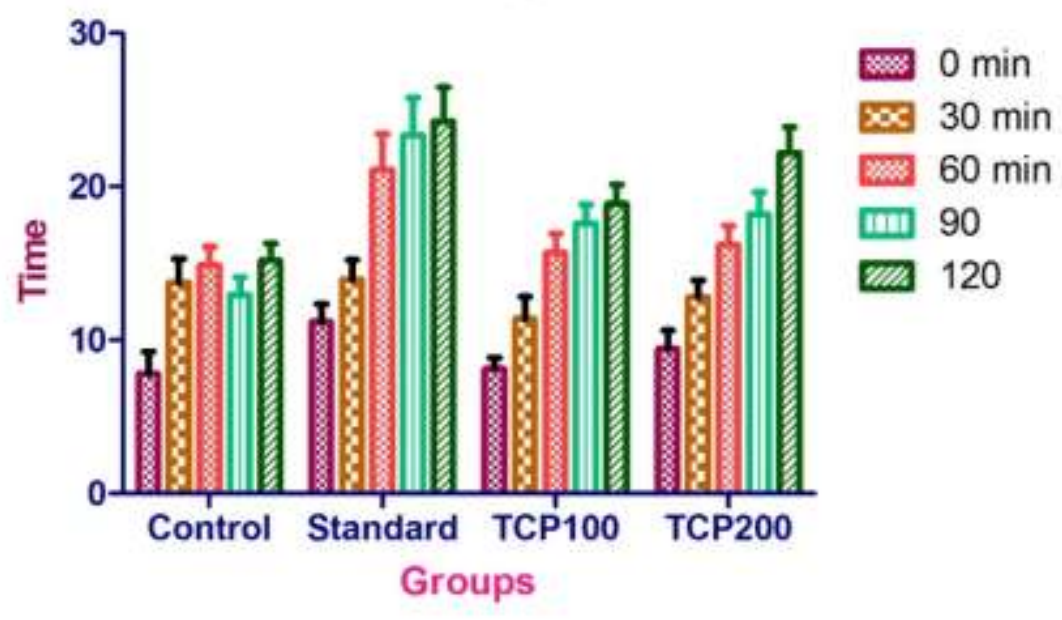

Figure 1. Effect of Thiriloga Chindhamani Pills on latency to hot plate test

\section{Anti-inflammatory Activity}

\section{Carrageenan-Induced Paw Edema in rats}

The anti-inflammatory effect of Thiriloga Chindhamani pills on Carrageenan induced hind paw edema as shown in Table 2 and Figure 2. The volume of the oedema induced by 
carrageenan increases with time until the fifth hour. The results showed that there was a significant different in oedema size between all the tested groups after the one hour treatment. Thiriloga Chindhamani pills at doses $100 \mathrm{mg} / \mathrm{kg}$ produced a significant acute antiinflammatory effect against Carrageenan induced inflammation after $3.0 \mathrm{~h}$ of the administration compared to the control. TCP 200 exhibited highly significant effect (percentage of inhibition of $51.52 \%$ after $5.0 \mathrm{~h}$ ) which is similar to that of standard drug. (Table $3)$.

Table 2. Effect of TCP on Carrageenan induced paw edema in rats.

\begin{tabular}{cllllll}
\hline Group & \multicolumn{4}{l}{ Initial paw volume } & \multicolumn{4}{l}{ Change in paw edema $\mathbf{m m}$ at different time intervals } \\
& $\mathbf{0 h r}$ & $\mathbf{1 ~ h r}$ & $\mathbf{2 h r}$ & $\mathbf{3 h r}$ & $\mathbf{4 h r}$ & $\mathbf{5 h r}$ \\
\hline Control & $1.20 \pm 0.14$ & $1.20 \pm 0.14$ & $1.20 \pm 0.14$ & $1.20 \pm 0.14$ & $1.20 \pm .14$ & $1.20 \pm 0.14$ \\
Negative & $1.21 \pm 0.17$ & $1.91 \pm 0.21$ & $2.27 \pm 0.02$ & $2.37 \pm 0.14$ & $2.48 \pm 0.18$ & $2.62 \pm 0.17$ \\
Standard & $1.25 \pm 0.01$ & $1.40 \pm 0.26^{*}$ & $1.36 \pm 0.01^{*}$ & $1.28 \pm 0.18^{* *}$ & $1.27 \pm 0.05^{* *}$ & $1.23 \pm 0.26^{* *}$ \\
TCP 100 & $1.23 \pm 0.01$ & $1.69 \pm 0.26$ & $1.68 \pm 0.07$ & $1.65 \pm 0.25^{*}$ & $1.39 \pm 0.28^{*}$ & $1.32 \pm 0.46^{*}$ \\
TCP 200 & $1.24 \pm 0.01$ & $1.67 \pm 0.07$ & $1.57 \pm 0.13$ & $1.35 \pm 0.13^{*}$ & $1.33 \pm 0.12^{*}$ & $1.27 \pm 0.02^{* *}$ \\
\hline
\end{tabular}

The paw volume up to the tribiotural articulation was measured at $0,1,2,3,4,5 \mathrm{hrs}$. Data are represented as the mean $\pm \operatorname{SEM},(n=6) ;{ }^{*} p<0.05, * * p<0.01$ were considered significant in comparison with control.

\section{Effect of TCP on Carrageenan induced paw edema in rats}

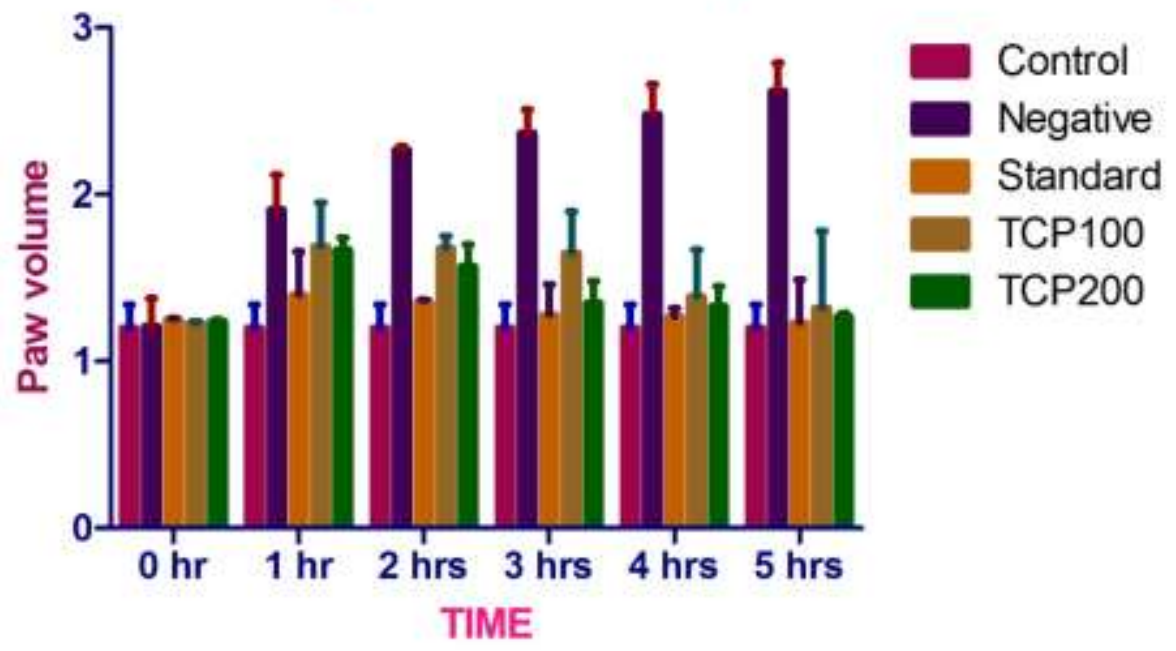

Figure 2. Effect of TCP on Carrageenan induced paw edema in rats.

Table 3. Percentage of protection by the trial drug Thiriloga Chindhamani pills

\begin{tabular}{lllll}
\hline Group & $\begin{array}{l}\text { Initial paw } \\
\text { volume }\end{array}$ & $\begin{array}{l}\mathbf{5} \text { hr in } \\
\mathbf{m m}\end{array}$ & $\begin{array}{l}\text { Difference in } \\
\text { paw volume }\end{array}$ & $\begin{array}{l}\text { Percentage } \\
\text { protection }\end{array}$ \\
\hline Control & $1.20 \pm 0.14$ & $1.20 \pm 0.14$ & 0.00 & 100 \\
Negative & $1.21 \pm 0.17$ & $2.62 \pm 0.17$ & 1.41 & - \\
Standard & $1.25 \pm 0.01$ & $1.23 \pm 0.26$ & 0.02 & 53.05 \\
TCP 100 & $1.23 \pm 0.01$ & $1.32 \pm 0.46$ & 0.04 & 49.61 \\
TCP 200 & $1.24 \pm 0.01$ & $1.27 \pm 0.02$ & 0.01 & 51.52 \\
\hline
\end{tabular}


Percentage protection is calculated by the formulae: $\left(\mathrm{V}_{\mathrm{c}^{---}} \mathrm{V}_{\mathrm{t}} \mathrm{V}_{\mathrm{c}}\right) \times 100 \quad \mathrm{~V}_{\mathrm{c}^{--}}$control;

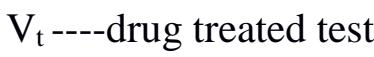

\section{Anti-arthritic activity}

\section{Evaluation of edema / thickness of the leg}

Freund's complete adjuvant injected rats developed arthritis rapidly with clinical signs such as redness, edema and swelling in the joints of the feet. Table 4 and Figure 3 showed the result of the anti-arthritic activity of TCP at a dose of $100 \mathrm{mg}$ and $200 \mathrm{mg} / \mathrm{kg}$ of body weight through the evaluation of oedema / thickness of the legs of the experimental animals during $1^{\text {st }}$ day to 28th days of experimental period. The trial drug TCP showed a significant difference in edema and thickness of leg compared to the arthritic control from the eighth day of its administration. TCP 100 showed significant activity only on $14^{\text {th }}, 21^{\text {st }}$ and $28^{\text {th }}$ day of treatment, whereas TCP 200 significantly decrease the inflammation from eighth day itself and highly significant on $14^{\text {th }}, 21^{\text {st }}$ and $28^{\text {th }}$ day of treatment which showed its dose dependent activity. The standard group (prednisolone) that showed the significant effect in $8^{\text {th }}$ days and highly significant effect in $14^{\text {th }}, 21^{\text {st }}$ and $28^{\text {th }}$ days. The anti-arthritic activity of prednisolone being generally greater when compared to the test groups (TCP 100 and TCP 200).

Table 4. Effect of TCP on injected paw volume in Freund's complete adjuvant induced arthritic rats

\begin{tabular}{lllllll}
\hline Group & $\begin{array}{l}\text { Volume/ml } \\
\text { Day 0 }\end{array}$ & $\begin{array}{l}\text { Volume/ml } \\
\text { Day 4 }\end{array}$ & $\begin{array}{l}\text { Volume/ml } \\
\text { Day 8 }\end{array}$ & $\begin{array}{l}\text { Volume/ml } \\
\text { Day 14 }\end{array}$ & $\begin{array}{l}\text { Volume/ml } \\
\text { Day 21 }\end{array}$ & $\begin{array}{l}\text { Volume/ml } \\
\text { Day 28 }\end{array}$ \\
\hline Control & $1.11 \pm 0.4$ & $1.12 \pm 0.4$ & $1.13 \pm 0.4$ & $1.11 \pm 0.5$ & $1.11 \pm 0.4$ & $1.11 \pm 0.5$ \\
Negative & $1.12 \pm 0.8$ & $1.24 \pm 0.6$ & $1.28 \pm 0.10$ & $1.44 \pm 0.10$ & $1.43 \pm 0.5$ & $1.44 \pm 0.4$ \\
TCP 100 & $1.22 \pm 0.7$ & $1.34 \pm 0.6$ & $1.20 \pm 0.5$ & $1.18 \pm 0.2^{*}$ & $1.12 \pm 0.5^{*}$ & $1.12 \pm 0.6^{*}$ \\
TCP 200 & $1.20 \pm 0.8$ & $1.20 \pm 0.20$ & $1.12 \pm 0.3^{*}$ & $1.10 \pm 0.6^{* *}$ & $1.11 \pm 0.3^{* *}$ & $1.10 \pm 0.3^{* *}$ \\
Standard & $1.22 \pm 0.7$ & $1.16 \pm 0.4$ & $1.12 \pm 0.5^{*}$ & $1.10 \pm 0.5^{* *}$ & $1.08 \pm 0.4^{* *}$ & $1.07 \pm 0.6^{* *}$ \\
\hline \multicolumn{7}{c}{ Values are expressed as Mean \pm SEM; $N=6 ;) ; *^{*}<0.05, *^{*} p<0.01 v$ Oday }
\end{tabular}




\section{Effect of TCP on injected paw volume in FCA induced arthritic rats}

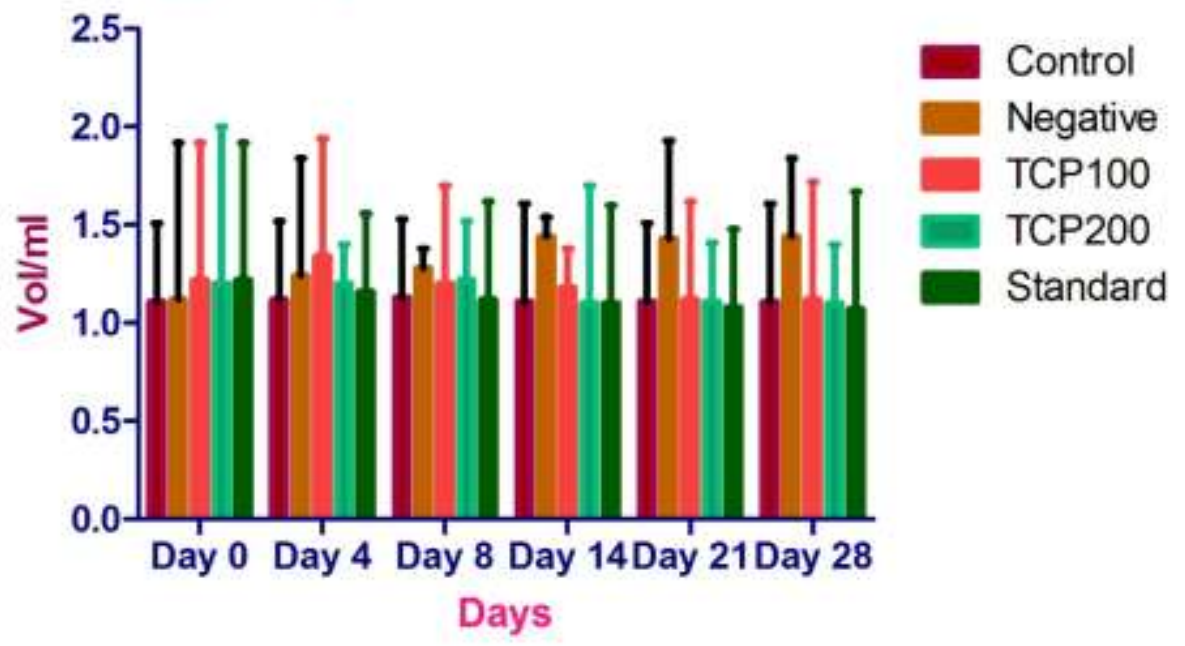

Figure 3. Effect of TCP on injected paw volume in Freund's complete adjuvant induced arthritic rats

\section{Evaluation of body weight}

Table 5 shows the results of the evaluation of TCP on weights by the arthritis induction model by injection of Freund's complete adjuvant after 28 days of administration of TCP. After induction of arthritis, the body weight of the TCP treated groups and standard drug group slightly increased on $28^{\text {th }}$ day as compared with the initial body weight and there were no statistically significant. Increased body weight in all treated groups were in a normal manner. Whereas the body weight of the arthritic control group gradually and significantly decreased during the experimental period. It may be due to anorexia caused by pain and inflammation of joints of arthritic control groups.

Table 5: Effect of Thiriloga Chindhamani pills on body weight in arthritic rats

\begin{tabular}{llll}
\hline Groups & $\begin{array}{l}\text { Mean B.W (gm) } \\
\text { Before induction }\end{array}$ & After induction & $\begin{array}{l}\text { Mean Difference } \\
\text { in B.W }\end{array}$ \\
\hline Normal & $161 \pm 2.0$ & $177 \pm 2.1$ & $16 \pm 0.1$ \\
Control (RA) & $165 \pm 3.13$ & $174 \pm 3.2$ & $09 \pm 0.07$ \\
TCP 100 & $156 \pm 2.2$ & $172 \pm 2.8$ & $16 \pm 0.6^{*}$ \\
TCP 200 & $159 \pm 1.8$ & $176 \pm 2.6$ & $17 \pm 0.8^{* *}$ \\
Standard & $157 \pm 1.7$ & $175 \pm 3.0$ & $18 \pm 1.3^{* *}$ \\
\hline
\end{tabular}

Values are expressed as Mean \pm SEM; $N=6 ;) ; * p<0.05$, $* * p<0.01 v$ s negative control

\section{Articular index}

TCP100 and TCP200 treatment significantly decrease the articular index on $28^{\text {th }}$ day of treatment which indicated a significant decrease in the oedema associated with the adjuvantinduced arthritis (Table 6). The reduction in the articular index score was greater in the standard drug (Prednisolone $10 \mathrm{mg} / \mathrm{kg}$ )-treated group as compared with the TCP100 and TCP200 groups. 
Table 6. Articular index of TCP

\begin{tabular}{lll}
\hline S.no & Group & Articular index on day 28 \\
\hline 1 & Control & 0 \\
2 & Arthritic control & $4.8 \pm 1.11$ \\
3 & TCP 100mg & $3.6 \pm 1.10^{*}$ \\
4 & TCP 200mg & $2.8 \pm 2.24 *$ \\
5 & Prednisolone & $1.2 \pm 1.28^{* *}$ \\
\hline
\end{tabular}

Values are expressed as Mean \pm SEM; $N=6 ;) ; *^{*}<0.05, * * p<0.01 v s$ negative control

\section{Hematological parameters}

The hematological parameters evaluated in experimental animals were: WBC, RBC, ESR and hemoglobin. The hematological changes associated with arthritis are presented in Table 7.

Table 7. Effect of TCP on hematological parameters of arthritic rat

\begin{tabular}{lllll}
\hline Groups & Hemoglobin & Total RBC & Total WBC & ESR (60 min) \\
\hline Normal & $17.39 \pm 0.27$ & $6.32 \pm 0.10$ & $5.09 \pm 0.68$ & $0.96 \pm 0.02$ \\
Arthritic control & $15.43 \pm 0.36^{*}$ & $5.61 \pm 0.13^{*}$ & $9.13 \pm 1.52^{* *}$ & $2.25 \pm 0.16^{* *}$ \\
Prednisolone & $17.38 \pm 0.45$ & $6.32 \pm 0.16^{*}$ & $4.44 \pm 0.44^{*}$ & $0 \pm 0$ \\
TCP 100 & $19.14 \pm 0.45^{*}$ & $6.92 \pm 0.18$ & $6.92 \pm 1.01$ & $1 \pm 0$ \\
TCP 200 & $18.12 \pm 0.51$ & $6.54 \pm 0.18^{*}$ & $5.98 \pm 0.56^{*}$ & $1 \pm 0$ \\
\hline
\end{tabular}

Data are represented as the mean \pm SEM, $(n=6) ; * p<0.05, * * p<0.01$ were considered significant in comparison with control.

The results obtained were compared with the hematological values obtained in healthy rats (negative control), in arthritic rats (untreated rats) and in arthritic rats treated with prednisolone (control drug) and two test groups (TCP 100 and TCP 200). After 28 days of experimental study, there was significant increase in the total WBC and ESR $(P<0.05)$, and significant decrease in $\mathrm{Hb}$ level and $\mathrm{RBC}$ count $(P<0.05)$ of arthritic control animals as compared to normal rats. However, the treatment with TCP $(100$ and $200 \mathrm{mg} / \mathrm{kg})$ showed a significant increase in the $\mathrm{Hb}$ and $\mathrm{RBC}$ count $(P<0.05)$ when compared to control group. At the same time, the standard drug group (prednisolone $10 \mathrm{mg} / \mathrm{kg}$ ) significantly increase of $\mathrm{Hb}$ and $\mathrm{RBC}$ level and decrease in WBC and ESR level at the end, their values were close to that of normal animals.

\section{DISCUSSION}

\section{Analgesic activity}

The hot plate test is one of the commonly used test for investigating analgesic activity using thermal pain stimuli. It is rapid and precise model for screening analgesic drugs in laboratory animals. TCP administered orally to rats at doses of 100 and $200 \mathrm{mg} / \mathrm{kg}$ raises the pain threshold on the hotplate. With the dose of TCP $200 \mathrm{mg} / \mathrm{kg}$, the increase in the pain threshold was highly significant compared to the control group. The results obtained in this study that appear dose-dependent confirm that this analgesic activity of TCP. The inhibition of the production or release of the pro-inflammatory cytokines TNF- $\alpha$, IL-1, and IL-6 has been 
associated with anti-nociceptive effects $\left({ }^{20}\right)$. It is highly likely that TCP interferes with the biosynthesis of pro-inflammatory cytokines like standard non-steroidal anti-inflammatory drug diclofenac sodium.

Reducing the biological activity of proinflammatory cytokine can reduce the brunt of attack from diseases $\left({ }^{21}\right.$ ) Blocking IL-1 or TNF- $\alpha$ has been highly successful in helping patients with rheumatoid arthritis, inflammatory bowel disease $\left({ }^{22}\right)$.

\section{Anti-inflammatory activity}

The screening of the anti-inflammatory activity is carried out by the carrageenan test. This phlogogenic substance induces at the paw edema considered a characteristic sign of inflammation and this assay is mostly accepted as useful phlogistic agent for the investigation of new anti-inflammatory drugs such as evaluation of the anti-inflammatory activity of several herbo-mineral formulations from traditional sources $\left({ }^{23}\right)$.

Carrageenan causes a local inflammation, when injected in aponeurosis of the sole of the foot because tissue injury. The injection of the carrageenan causes the release of several chemical mediators that are responsible for the inflammatory process by increased vascular permeability and oedema.

The acute inflammatory responses induced after carrageenan injection involves biphasic inflammatory phases through the release of several inflammatory mediators. In the experimental conditions the Carrageenan caused an oedema volume is maximal after $3-5$ hours and subsides by 24 hours $\left({ }^{24}\right)$.

The results of anti-inflammatory activity of TCP100 and TCP200 were compared to standard drug indomethacin $40 \mathrm{mg} / \mathrm{kg}$, one of the potent anti-inflammatory drug and those of normal control. In the present study, TCP 100 and 200 exhibited significant anti-inflammatory activity. It has been observed that the second phase is found to be sensitive to the trial drug TCP 100 and $200 \mathrm{mg}$. In the present study, TCP showed dose-dependent inhibition of second phase of carrageenan induced rat paw oedema, suggesting the inhibition of prostaglandins release. This anti-inflammatory activity has been maintained throughout the duration of experimentation with two different doses $(100 \mathrm{mg} / \mathrm{kg}$ and $200 \mathrm{mg} / \mathrm{kg}$ ) of TCP. The obtained results could be attributed to the presence of mercury, sulphur and borax that would inhibit inflammation.

\section{Anti-arthritic activity}

CFA-induced arthritis is the most widely used chronic test model which was developed by Pearson $\left({ }^{25}\right)$ in which the clinical and pathological changes are comparable with those seen in human rheumatoid arthritis $\left.{ }^{26}\right)$. The main pathological features of CFA induced arthritis which include synovial hyperplasia and cartilage degradation observed in human arthritis, particularly RA $\left({ }^{27-29}\right)$. Arthritis is induced in susceptible strains of rats by injecting heat-killed 
mycobacterium tuberculosis $\left({ }^{30}\right)$ which causes localized inflammation of the joints associated with hypertrophy of the synovial membrane and the progressive and irreversible destruction of the cartilage ${ }^{31,32}$ ).Paw swelling is an index of measuring the anti-arthritic activity of TCP at the dose level 100 and 200mg/kg/p.o. TCP treated groups (TCP100 and TCP200) showed significant reduction in paw volume when compared with the arthritic control group. It was also found that there was significant weight loss following the injection of the Freund's adjuvant, but thereafter continued to show normal weight gain in rats.

The reduction of the articular index score by the administration of TCP in rats revealed that a possible immunosuppressant effect may play in a key role by reducing the arthritic severity. Observation of body weight changes, there was restoration of the body weight by administration of TCP 100, TCP200 and standard drug, because of the normalization of metabolic process and reduction of discomfort caused by the inflammatory process. Observation of haematological parameters during the study showed that $\mathrm{Hb}$, TRBC and WBC count of TCP and standard drug treated groups appears to be normal. ESR was also restored by the above treated groups.

Thiriloga Chindhamani Pills (TCP) is one of the herbo-mineral preparation in Siddha system of medicine which have potent anti-inflammatory properties probably due to the inhibition of pro inflammatory mediators include prostaglandin, bradikinins and leukotrienes synthesis. Physico chemical analysis revealed the presence of mercury, sulphur and borax in TCP. These compounds are known to possess analgesic, anti-inflammatory and anti-arthritic effects due to their inhibitory effect on enzymes involved in. the production of mediators of inflammation activity.

Boron is a successful treatment option for arthritis. With its anti-inflammatory powers already being recognized by Indian system of medicine. Research suggested that those with arthritis have lower boron concentrations in their bones along with synovial fluid, and femur heads $\left({ }^{33}\right)$. Thus use of Boron can stem this. Boron ensures that calcium levels are maximized and used effectively, thus preventing arthritis. Mercury, sulphur and borax combination of other siddha herbo mineral preparation such as Gowri Chindhamani did not produce any toxicity in laboratory animals $\left({ }^{34}\right)$. No changes in anatomical and behavioural profiles as well as body and organ weights were seen. No histopathological changes were noticed $\left({ }^{35}\right)$.

\section{CONCLUSION}

Analgesic, anti-inflammatory and anti-arthritic activities of two doses of (TCP100 and TCP200mg/kg) Thiriloga Chindhamani Pills were carried out in animal models. The profiles of the analgesic activity reveal that the TCP tested have a dose-dependent activity. Acute antiinflammatory activity was examined for TCP by carrageenan induced animal model and anti- 
arthritic activity by CFA-induced arthritis in rats. After induction of arthritis by Freund's complete adjuvant, treatment with Thiriloga Chindhamani Pills, caused a significant decrease ( $\mathrm{p}<0.05$ ) in the volume of Edema of the feet of the rats treated with the dose $100 \mathrm{mg} / \mathrm{kg}$ of Thiriloga Chindhamani Pills. This improvement is accompanied by normalization of the number of leukocytes, heamoglobin, RBC and ESR in rats. While the dose $200 \mathrm{mg} / \mathrm{kg}$ decreases very significantly ( $\mathrm{p}<0.01$ ) the $\mathrm{Hb}, \mathrm{RBC}, \mathrm{WBC}$ and ESR levels showing the dosedependent effect of the Pills. According to the results of the study, it can be concluded that Thiriloga Chindhamani Pills has an analgesic, anti-inflammatory and anti-arthritic property. However, further study will be carried out to understand the exact mechanism in search of active chemical substances that is mainly responsible for this above said activity through detailed scientific experiments.

\section{ACKNOWLEDGEMENT}

The authors are thankful to the all teaching staff of Gunapadam (Pharmacology), Government Siddha Medical College, Chennai for their constant encouragement, support and guidance. I thank Tamilnadu Dr.M.G.R. Medical University, Guindy, Chennai for giving me a chance to publish this article as a part of my dissertation.

\section{REFERENCES}

1. Chronic diseases and health promotions. Chronic rheumatic conditions. Rheumatoid arthritis. World Health organization. https://www.who.int/chp/topics/rheumatic/en/.

2. "Handout on Health: Rheumatoid Arthritis". National Institute of Arthritis and Musculoskeletal and Skin Diseases. August 2014. Archived from the original on June 30, 2015. Retrieved July 2, 2015.

3. Majithia V, Geraci SA. "Rheumatoid arthritis: diagnosis and management". Am. J. Med. 2007; 120 (11): 936-9.

4. Global, regional, and national incidence, prevalence, and years lived with disability for 310 diseases and injuries (1990-2015). A systematic analysis for the global burden of disease study 2015. Lancet 89388(10053): 1545-1602.

5. Smolen, Josef S.; Aletaha, Daniel; McInnes, Iain B. (2016-10-22). "Rheumatoid arthritis". Lancet. 388 (10055): 2023-2038.

6. Global, regional, and national age-sex specific all-cause and cause-specific mortality for 240 causes of death, 1990-2013: a systematic analysis for the global burden of disease study 2013. Lancet 17 385(9963): 117-171.

7. Gupta B, Ritu G, Ashok K, Madhu B. Rheumatoid Arthritis Research in India: A Scientometric Assessment of Publications during 2007-2016 .Ortho Res Online J. 3(1). 
8. "Rheumatoid arthritis in adults: management: recommendations: Guidance and guidelines". NICE. December 2015. Archived from the original on 2017-04-16.

9. Singh, JA; Saag, KG; Bridges SL, Jr; Ak 1; et al. "2015 American College of Rheumatology Guideline for the Treatment of Rheumatoid Arthritis". Arthritis \& Rheumatology. 2016; 68 (1): 1-26.

10. Singh, JA; Wells, GA; Christensen, R; et al. "Adverse effects of biologics: a network meta-analysis and Cochrane overview". The Cochrane Database of Systematic Reviews (2):2011; CD008794.

11. S.P.Ramachandran. Veeramamunivar Vagada Thirattu. Published by Thamarai Noolagam, 115-116.

12. Thiagarajan. Text Book of Materia Medica (Gunapadam)- Thathu \& Jeevam, published by Department of Indian Medicine and Homoeopathy, Reprinted 2008; 250.

13. Murugesan Mudhaliyar K.S. Gunapadam Mooligai Vaguppu, Indian Medicine and Homeopathy Dept, Reprinted in 2003, Chennai-106, 357.

14. Lanhers, M.C., J. Fleurentin, F. Mortier, A. Vinche and C. Younos. Anti-inflammatory and analgesic effects of an aqueous extract of Harpagophytum procumbens. Planta Med., 1992; 58: 117-123.

15. Ojewole, J.A.O., Evaluation of the analgesic, anti-inflammatory and anti-diabetic properties of Sclerocarya birrea (A. Rich.) Hochst. Stem-bark aqueous extract in mice and rats. Phytotherapy Res., 2004; 18: 601-608.

16. Winter, C.A., E.A. Risley and G.W. Nuss. Carrageenan-induced oedema in hind paw of the rat as an assay for anti-inflammatory drugs. Proc. Soc. Exp. Biol. Med., 1962; 111: 544-547.

17. Singh GB, Singh S, Bani S, Gupta BD, Banerjee SK. Anti-inflammatory activity of oleanolic acid in rats and mice. J. Pharm. Pharmacol. 1992; 44, 456-8.

18. Joseph E. Baggott Sarah L. Morgan William J. Koopman. The effect of methotrexate and 7-hydroxymethotrexate on rat adjuvant arthritis and on urinary amino imidazole carboxamide excretion. Arthritis Rheum. 1998; 41:1407-1410.

19. Mate, G.S. Naikwade, N.S. Magdum, C.S. Chowki, A.A. Patil, S.B. Evaluation of antinociceptive activity of Cissus quadrangularis on albino mice. Int J. Green pharma. $2008 ; 118-121$.

20. Da Silva KA, Paszcuk AF, Passos GF, Silva ES, Bento AF, Meotti FC, et al. Activation of cannabinoid receptors by the pentacyclic triterpene $\alpha, \beta$-amylin inhibits inflammatory and neuropathic persistent pain in mice. Pain. 2011; 152:1872-87. 
21. Dinarello CA. "Proinflammatory cytokines". Chest. 2000; 118 (2): 503-8.

22. Strober W, Fuss IJ (May 2011). "Proinflammatory cytokines in the pathogenesis of inflammatory bowel diseases", Gastroenterology. 140 (6): 1756-67.

23. Sindhu G, Ratheesh M, Shyni GL, Nambisan B, Helen A. Anti-inflammatory and antioxidative effects of mucilage of Trigonella foenum graecum (Fenugreek) on adjuvant induced arthritic rats. Int Immunopharmacol. 2012; 12:205-11.

24. Winter CA, Risley EA, Nuss GW. Carrageenan-induced oedema in hind paw of the rat as an assay for anti-inflammatory drugs. Proc Soc Exp Biol Med. 1962; 111:544-7.

25. C. M. Pearson. "Development of arthritis, periarthritis and periostitis in rats given adjuvants," Experimental Biology and Medicine.1956; vol. 91, no. 1, 95-101.

26. Shinde UA, Phadake AS, Nair AM, Mungantiwar AA, Dishit VJ, Saraf MN. Studies on the anti-inflammatory and analgesic activity of Cedrus deodara (Roxb) Loud, Wood oil. J.Ethnopharmacol 1999; 65: 21-28.

27. Bendele, J. Mccomb, T. Gould et al., "Animal models of arthritis: relevance to human disease," Toxicologic Pathology.1999; vol. 27, no. 1, 134-142.

28. Bendele A., Mccomb J., Gould T., et al. Animal models of arthritis: relevance to human disease, Toxicologic Pathology. 1999; 27(1):134-142.

29. Taurog J. D., Argentieri D. C., McReynolds R. A. Adjuvant arthritis, Methods in Enzymology. 1988; 162:339-355.

30. M. Durai, H. R. Kim, and K. D. Moudgil. "The regulatory C-terminal determinants within mycobacterial heat shock protein 65 are cryptic and cross-reactive with the dominant self-homologs, implications for the pathogenesis of autoimmune arthritis," The Journal of Immunology, vol. 173, 2004; no. 1, 181-188.

31. Roberts L, McColl GJ. Tumour necrosis factor inhibitors, Risks and benefits in patients with rheumatoid arthritis. Intern Med J. 2004; 34:687-93.

32. Klinkhoff A. Biological agents for rheumatoid arthritis, Targeting both physical function and structural damage. Drugs. 2004; 64:1267-83.

33. Newnham RE. Essentiality of boron for healthy bones and joints, Environ Health Perspect. 1994 Nov; 102 Suppl 7:83-5.

34. $\mathrm{P}$ Shanmugapriya, S Thamodharan, M Ramamurthy, VCJ Mol, M Nijavizhi. Toxicological Screening of Gowri Chindhamani Chendooram, A Siddha Metallic Preparation. PharmaTutor; 2014; 2(9); 119-122. 
35. Ilango, Bharathidasan \& Krishnamurthy, Vinoth \& Raman, Rajkumar \& Sukumar, E. Effect of a mercurial drug of siddha medicine on haematological, biochemical and antioxidant status in rats. Indian Journal of Traditional Knowledge, 2018; 17. 480-484.

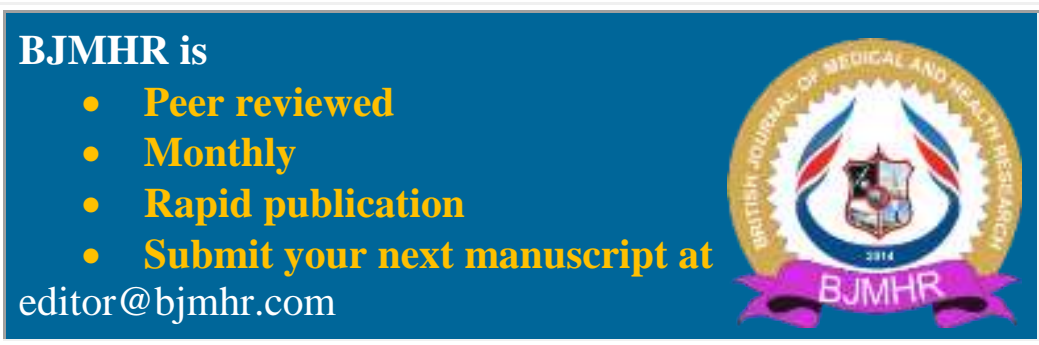

